\title{
An Experimental and Theoretical Investigation of the Mechanical Behavior of Multilayer Initially Curved Microplates Under Electrostatic Actuation
}

\author{
S. Saghir, ${ }^{\mathrm{a}, \mathrm{b}}$ S. Ilyas, ${ }^{\mathrm{a}}$ N. Jaber, ${ }^{\mathrm{a}}$ and M.I. Younis ${ }^{\mathrm{a}, *}$ \\ a 4700 King Abdullah University of Science and Technology (KAUST), Thuwal 23955-6900, Saudi Arabia \\ ${ }^{\mathrm{b}}$ University of Management and Technology (UMT), Daska Road, Sialkot, Pakistan \\ *Corresponding author, mohammad.younis@kaust.edu.sa
}

\begin{abstract}
We investigate the static and dynamic behavior of a multilayer clamped-free-clamped-free (CFCF) microplate, which is made of polyimide, gold, chromium, and nickel. The microplate is slightly curved away from a stationary electrode and is electrostatically actuated. The free and forced vibrations of the microplate are examined. First, we experimentally investigate the variation of the first natural frequency under the electrostatic DC load. Then, the forced dynamic behavior is investigated by applying a harmonic AC voltage superimposed to a DC voltage. Results are shown demonstrating the transition of the dynamic response of the microplate from hardening to softening as the DC voltage is changed as well the dynamic pull-in phenomenon. For theoretical model, we adopt a dynamic analog of the von-Karman governing equations accounting for initial curvature imperfection. These equations are then used to develop a reduced order model based on the Galerkin procedure to simulate the mechanical behavior of the microplate. We compare the theoretical results with experimental data and show excellent agreement among the results. We also examine the effect of the initial rise on the natural frequencies of first three symmetric-symmetric modes of the plate.
\end{abstract}


Keywords: vibration of plates, reduced order model, imperfect plates, electrostatic actuation, nonlinear oscillation

\section{Introduction}

MEMS microplates are used in many applications, such as pressure, mass and gas sensors, micropumps , and microphones [1-7]. They commonly experience slight initial curvature imperfection due to the residual stresses caused by the micro-fabrication process [8-10]. They may also be fabricated with an initial curvature on purpose to realize the bi-stability attributes, which may be desired for MEMS applications $[11,12]$. Such initial curvatures introduce quadratic nonlinear terms into the governing equations, which weakens and competes with the hardening effect from mid-plane stretching $[9,13]$. Models based on the governing equations of planar structures, such as the von-Karman equations without accounting for the initial curvature imperfection show significant deviation from the actual responses [9].

In this article we investigate the mechanical behavior of a clamped-free-clamped-free multilayer microplate under electrostatic actuation. Microplates with these boundary conditions are commonly used similar to the classic clamped-clamped beams and bridges for pumping, switching, and sensing applications (due to their large surface area). The microplate has acquired a slight initial curvature during the fabrication process, and the deposition of different layers of materials at various temperatures, and is bent away from the stationary electrode contrary to the previous work where the microplate was bent towards the electrostatic electrode [9]. It comprises of five material layers, where polyimide is the main structural material sandwiched by a layer of nickel on the top and three layers of chromium and gold on the bottom in the order of chromium-gold-chromium [14]. Although skin layers are very thin as compared to the main structural material, yet the flexural rigidity of the sandwich structures is significantly higher than the single material structures [15]. This paper not only completes the overall mechanical behavior understanding of the initially imperfect microplates but also provides extensive experimental data along 
with accurate modeling of the equivalent flexural rigidity of the multiple material layers of the microplate. The microplate is bent away from the electrostatic electrode contrary to the previous work in [9].

There are several works reported on the study of initially curved 1-D structures such as microbeams and microarches under electrostatic actuation [8, 10, 12, 16-19]. On the other hand, there are limited number of studies reported on the investigation of initially curved microplates under electrostatic force, due to the complexity of the problem $[9,11]$. Medina et al [11] have recently discussed the static snap through of bistable initially curved circular microplates. Saghir et al. [9] presented an experimental and theoretical investigation of the mechanical behavior of initially curved rectangular microplates made of silicon nitride. The considered configuration of the microplate exhibited a curvature towards the stationary electrode.

Although there are only few studies reported on the initially curved microplates under electrostatic forces there are a number of works reported on the studies of initially curved macro-plates. For instance, Celep $[20,21]$ made an early attempt to investigate the dynamic behavior of imperfect plates. They conducted a free vibration analysis of such plates with various boundary conditions. Yamaki et al [22, 23] presented theoretical analyses and experimental results for the nonlinear vibrations of a fully clamped rectangular plate with initial deflection and initial edge displacement. The nonlinear response of simply supported initially deformed plates was investigated by Marin et al [24], Lin and Chen [25], and Ostiguy et al [26]. It was concluded that the vibration frequencies are very much dependent on the initial imperfection of the plate and the large amplitude behavior may change drastically from hardening to softening depending on the initial imperfection [25]. Alijani and Amabili [13] have investigated the large amplitude vibration of completely free imperfect rectangular plates using the higher-order shear deformation theory.

Several works are reported on the studies of planar microplates under electrostatic actuation [4, 27-34]. Machauf et al. [4] studied the characteristics of an electrostatically actuated micropump using the linear plate theory. Faris et al. [7] presented a model for a micropump based on electrostatically actuated annular 
plates. The model predicts the deflection accurately for any voltage up to the pull-in voltage. Chao and co-workers [27] used the linear plate theory to model a fully clamped thin plate under electrostatic pressure. Vogl and Nayfeh [35] presented an analytical reduced order model (ROM) for fully clamped electrostatically actuated circular plates. The model accounted for the geometric nonlinearity and residual stresses. Zhao et al. [29] presented a ROM model for electrostatically actuated rectangular microplates. The model accounted for the nonlinearities due to the electric force and mid-plane stretching through the von Karman strains. Saghir and Younis [30,31] have investigated the static and dynamic behavior of mono-layer flat and fully clamped rectangular microplates under electrostatic actuation.

From the aforementioned literature review, one can note the lack of sufficient theoretical and experimental data for the dynamic behavior of initially curved microplates, particularly under electrostatic forces. No works have been reported on the mechanical behavior of multilayer initially curved microplates under electrostatic actuation. Such microplates are frequently used in practical MEMS applications and their natural frequencies and mechanical behavior needs to be studied. Large body of the literature is on the studies of planar microplates or macro-plates without consideration of electrostatic forces. In this study, we present experimental and theoretical investigation and data of a multilayer initially curved microplate comprising of five structural layers. A macro-model is built using the Galerkin procedure based on the dynamic analog of von-Karman equations, which account for the initial curvature imperfection, the nonlinear electrostatic loading, and midplane stretching. Natural frequencies and forced vibration studies are presented. Finally, we show the impact of the initial rise of the plate on the first few natural frequencies of the plate.

The organization of the rest of the paper is as follows. Section 2 discusses the problem formulation and the nonlinear plate model used for the theoretical study. Section 3 outlines the reduced-order modeling steps. Section 4 details the fabrication process used to fabricate the microplate case studies. Section 5 starts with experimental data on the case studies and then compares the theoretical predictions with the 
experimental data to validate the derived model. Finally, Section 6 presents summary and concluding remarks for the paper.

\section{Problem Formulation}

We consider a clamped-free-clamped-free (CFCF) microplate having an initial curvature imperfection $w_{0}(x, y)$ and side lengths a and $\mathrm{b}$, respectively, Figure 1.

To model the microplate we adopt a dynamic analog of the von-Karman equations, which account for the initial curvature $[9,36]$.The governing equations can be written as

$$
\begin{aligned}
& \frac{\partial^{2} u}{\partial x^{2}}+\frac{1}{2}(1+v) \frac{\partial^{2} v}{\partial x \partial y}+\frac{1}{2}(1-v) \frac{\partial^{2} u}{\partial y^{2}}+\left(\frac{\partial w}{\partial x} \frac{\partial^{2} w}{\partial x^{2}}+\frac{\partial w_{0}}{\partial x} \frac{\partial^{2} w}{\partial x^{2}}+\frac{\partial w}{\partial x} \frac{\partial^{2} w_{0}}{\partial x^{2}}\right) \\
& +\frac{1}{2}(1+v)\left(\frac{\partial w}{\partial y} \frac{\partial^{2} w}{\partial x \partial y}+\frac{\partial w_{0}}{\partial y} \frac{\partial^{2} w}{\partial x \partial y}+\frac{\partial w}{\partial y} \frac{\partial^{2} w_{0}}{\partial x \partial y}\right)+\frac{1}{2}(1-v)\left(\frac{\partial w}{\partial x} \frac{\partial^{2} w}{\partial y^{2}}+\frac{\partial w_{0}}{\partial x} \frac{\partial^{2} w}{\partial y^{2}}+\frac{\partial w}{\partial x} \frac{\partial^{2} w_{0}}{\partial y^{2}}\right)=0 \\
& \frac{\partial^{2} v}{\partial y^{2}}+\frac{1}{2}(1+v) \frac{\partial^{2} u}{\partial x \partial y}+\frac{1}{2}(1-v) \frac{\partial^{2} v}{\partial x^{2}}+\left(\frac{\partial w}{\partial y} \frac{\partial^{2} w}{\partial y^{2}}+\frac{\partial w_{0}}{\partial y} \frac{\partial^{2} w}{\partial y^{2}}+\frac{\partial w}{\partial y} \frac{\partial^{2} w_{0}}{\partial y^{2}}\right) \\
& +\frac{1}{2}(1+v)\left(\frac{\partial w}{\partial x} \frac{\partial^{2} w}{\partial x \partial y}+\frac{\partial w_{0}}{\partial x} \frac{\partial^{2} w}{\partial x \partial y}+\frac{\partial w}{\partial x} \frac{\partial^{2} w_{0}}{\partial x \partial y}\right)+\frac{1}{2}(1-v)\left(\frac{\partial w}{\partial y} \frac{\partial^{2} w}{\partial x^{2}}+\frac{\partial w_{0}}{\partial y} \frac{\partial^{2} w}{\partial x^{2}}+\frac{\partial w}{\partial y} \frac{\partial^{2} w_{0}}{\partial x^{2}}\right)=0 \\
& \frac{h^{2}}{12} \nabla^{4} w+\frac{\rho\left(1-v^{2}\right)}{E h} \frac{\partial^{2} w}{\partial t^{2}}+\frac{\hat{c}\left(1-v^{2}\right)}{E h} \frac{\partial w}{\partial t}=\frac{\varepsilon\left(1-v^{2}\right) V(t)^{2}}{2 E h\left(g-w_{0}-w\right)^{2}}+\frac{\left(1-v^{2}\right)}{E h}\left(N_{x x} \frac{\partial^{2} w}{\partial x^{2}}+2 N_{x y} \frac{\partial^{2} w}{\partial x \partial y}+N_{y y} \frac{\partial^{2} w}{\partial y^{2}}\right) \\
& +\frac{\partial u}{\partial x}\left(\frac{\partial^{2} w}{\partial x^{2}}+v \frac{\partial^{2} w}{\partial y^{2}}\right)+\frac{\partial v}{\partial y}\left(v \frac{\partial^{2} w}{\partial x^{2}}+\frac{\partial^{2} w}{\partial y^{2}}\right)+(1-v)\left(\frac{\partial u}{\partial y}+\frac{\partial v}{\partial x}\right) \frac{\partial^{2} w}{\partial x \partial y} \\
& +\frac{1}{2}\left(\frac{\partial w}{\partial x}\right)^{2}\left(\frac{\partial^{2} w}{\partial x^{2}}+v \frac{\partial^{2} w}{\partial y^{2}}\right)+\left(\frac{\partial w}{\partial x} \frac{\partial w_{0}}{\partial x}\right)\left(\frac{\partial^{2} w}{\partial x^{2}}+v \frac{\partial^{2} w}{\partial y^{2}}\right)+\frac{1}{2}\left(\frac{\partial w}{\partial y}\right)^{2}\left(v \frac{\partial^{2} w}{\partial x^{2}}+\frac{\partial^{2} w}{\partial y^{2}}\right) \\
& +\left(\frac{\partial w}{\partial y} \frac{\partial w_{0}}{\partial y}\right)\left(v \frac{\partial^{2} w}{\partial x^{2}}+\frac{\partial^{2} w}{\partial y^{2}}\right)+(1-v)\left(\frac{\partial w}{\partial x} \frac{\partial w}{\partial y} \frac{\partial^{2} w}{\partial x \partial y}+\frac{\partial w_{0}}{\partial x} \frac{\partial w}{\partial y} \frac{\partial^{2} w}{\partial x \partial y}+\frac{\partial w}{\partial x} \frac{\partial w_{0}}{\partial y} \frac{\partial^{2} w}{\partial x \partial y}\right) \\
& +\frac{\partial u}{\partial x}\left(\frac{\partial^{2} w_{0}}{\partial x^{2}}+v \frac{\partial^{2} w_{0}}{\partial y^{2}}\right)+\frac{\partial v}{\partial y}\left(v \frac{\partial^{2} w_{0}}{\partial x^{2}}+\frac{\partial^{2} w_{0}}{\partial y^{2}}\right)+(1-v)\left(\frac{\partial u}{\partial y}+\frac{\partial v}{\partial x}\right) \frac{\partial^{2} w_{0}}{\partial x \partial y} \\
& +\frac{1}{2}\left(\frac{\partial w}{\partial x}\right)^{2}\left(\frac{\partial^{2} w_{0}}{\partial x^{2}}+v \frac{\partial^{2} w_{0}}{\partial y^{2}}\right)+\left(\frac{\partial w}{\partial x} \frac{\partial w_{0}}{\partial x}\right)\left(\frac{\partial^{2} w_{0}}{\partial x^{2}}+v \frac{\partial^{2} w_{0}}{\partial y^{2}}\right)+\frac{1}{2}\left(\frac{\partial w}{\partial y}\right)^{2}\left(v \frac{\partial^{2} w_{0}}{\partial x^{2}}+\frac{\partial^{2} w_{0}}{\partial y^{2}}\right) \\
& +\left(\frac{\partial w}{\partial y} \frac{\partial w_{0}}{\partial y}\right)\left(v \frac{\partial^{2} w_{0}}{\partial x^{2}}+\frac{\partial^{2} w_{0}}{\partial y^{2}}\right)+(1-v)\left(\frac{\partial w}{\partial x} \frac{\partial w}{\partial y} \frac{\partial^{2} w_{0}}{\partial x \partial y}+\frac{\partial w_{0}}{\partial x} \frac{\partial w}{\partial y} \frac{\partial^{2} w_{0}}{\partial x \partial y}+\frac{\partial w}{\partial x} \frac{\partial w_{0}}{\partial y} \frac{\partial^{2} w_{0}}{\partial x \partial y}\right)
\end{aligned}
$$


where $u, v$ and $w$ are the displacements along $x, y$ and $z$ direction, respectively, $\nabla^{4}$ is the bi-harmonic operator given by $\nabla^{4}=\frac{\partial^{4}}{\partial x^{4}}+2 \frac{\partial^{4}}{\partial x^{2} \partial y^{2}}+\frac{\partial^{4}}{\partial y^{4}}, h$ is the plate thickness, $g$ is the parallel plate capacitor gap, $\rho$ is the mass density per unit area, $\hat{c}$ is the damping coefficient, $v$ and $E$ are the Poisson's ratio and modulus of elasticity, respectively. $V(t)$ is the applied voltage; it is either $V_{d c}$ for static analysis or a $V_{a c}$ superimposed to $V_{d c}$, i.e. $V(\mathrm{t})=V_{d c}+V_{a c} \operatorname{Sin}(\Omega \mathrm{t})$ where $\Omega$ is the actuating frequency. The first term in the right-hand side of equation (3) i.e. $\frac{\varepsilon\left(1-v^{2}\right) V(t)^{2}}{2 E h(g-w)^{2}}$ is the applied electric pressure in the transverse direction while $N_{i j}$ is the applied force per unit length on the edge perpendicular to the $i^{\text {th }}$ axis in the $j^{\text {th }}$ direction. The associated boundary conditions are

clamped edges at $x=0$ and $x=a$

$$
\begin{aligned}
& u=0 \\
& v=0 \\
& w=0 \\
& \frac{\partial w}{\partial x}=0
\end{aligned}
$$

free edges at $y=0$ and $y=b$

$$
\begin{aligned}
& \frac{\partial v}{\partial y}+v \frac{\partial u}{\partial x}+\frac{1}{2}\left[\left(\frac{\partial w}{\partial y}\right)^{2}+v\left(\frac{\partial w}{\partial x}\right)^{2}\right]=0 \\
& \frac{\partial u}{\partial y}+\frac{\partial v}{\partial x}+\frac{\partial w}{\partial x} \frac{\partial w}{\partial y}=0
\end{aligned}
$$




$$
\begin{aligned}
& \frac{\partial^{2} w}{\partial y^{2}}+v \frac{\partial^{2} w}{\partial x^{2}}=0 \\
& \frac{\partial^{3} w}{\partial y^{3}}+(2-v) \frac{\partial^{3} w}{\partial y \partial x^{2}}=0
\end{aligned}
$$

For convenience, we introduce the non-dimensional variables (denoted by hats);

$$
\hat{x}=\frac{x}{a}, \hat{y}=\frac{y}{b}, \hat{w}=\frac{w}{g}, \hat{u}=\frac{a u}{g^{2}}, \hat{v}=\frac{a v}{g^{2}}, \hat{t}=\frac{t}{T}
$$

Substituting equation (12) into equations (1)-(3) and dropping the hats for convenience we get the following equations:

$$
\begin{aligned}
& \frac{\partial^{2} u}{\partial x^{2}}+\frac{(1+v)}{2 \alpha} \frac{\partial^{2} v}{\partial x \partial y}+\frac{(1-v)}{2 \alpha^{2}} \frac{\partial^{2} u}{\partial y^{2}}+\left(\frac{\partial w}{\partial x} \frac{\partial^{2} w}{\partial x^{2}}+\frac{\partial w_{0}}{\partial x} \frac{\partial^{2} w}{\partial x^{2}}+\frac{\partial w}{\partial x} \frac{\partial^{2} w_{0}}{\partial x^{2}}\right) \\
& +\frac{(1+v)}{2 \alpha^{2}}\left(\frac{\partial w}{\partial y} \frac{\partial^{2} w}{\partial x \partial y}+\frac{\partial w_{0}}{\partial y} \frac{\partial^{2} w}{\partial x \partial y}+\frac{\partial w}{\partial y} \frac{\partial^{2} w_{0}}{\partial x \partial y}\right)+\frac{(1-v)}{2 \alpha^{2}}\left(\frac{\partial w}{\partial x} \frac{\partial^{2} w}{\partial y^{2}}+\frac{\partial w_{0}}{\partial x} \frac{\partial^{2} w}{\partial y^{2}}+\frac{\partial w}{\partial x} \frac{\partial^{2} w_{0}}{\partial y^{2}}\right)=0 \\
& \frac{\partial^{2} v}{\partial y^{2}}+\frac{(1+v) \alpha}{2} \frac{\partial^{2} u}{\partial x \partial y}+\frac{(1-v) \alpha^{2}}{2} \frac{\partial^{2} v}{\partial x^{2}}+\frac{1}{\alpha}\left(\frac{\partial w}{\partial y} \frac{\partial^{2} w}{\partial y^{2}}+\frac{\partial w_{0}}{\partial y} \frac{\partial^{2} w}{\partial y^{2}}+\frac{\partial w}{\partial y} \frac{\partial^{2} w_{0}}{\partial y^{2}}\right) \\
& +\frac{(1+v) \alpha}{2}\left(\frac{\partial w}{\partial x} \frac{\partial^{2} w}{\partial x \partial y}+\frac{\partial w_{0}}{\partial x} \frac{\partial^{2} w}{\partial x \partial y}+\frac{\partial w}{\partial x} \frac{\partial^{2} w_{0}}{\partial x \partial y}\right)+\frac{(1-v)}{2}\left(\frac{\partial w}{\partial y} \frac{\partial^{2} w}{\partial x^{2}}+\frac{\partial w_{0}}{\partial y} \frac{\partial^{2} w}{\partial x^{2}}+\frac{\partial w}{\partial y} \frac{\partial^{2} w_{0}}{\partial x^{2}}\right)=0 \\
& \frac{\partial^{4} w}{\partial x^{4}}+\frac{2}{\alpha^{2}} \frac{\partial^{4} w}{\partial x^{2} \partial y^{2}}+\frac{1}{\alpha^{4}} \frac{\partial^{4} w}{\partial y^{4}}+\frac{\partial^{2} w}{\partial t^{2}}+c \frac{\partial w}{\partial t}=\alpha_{2} \frac{V(t)^{2}}{(1-w)^{2}}+3 \alpha_{0}^{2}\left\{\hat{N}_{x x} \frac{\partial^{2} w}{\partial x^{2}}+\frac{2}{\alpha} \hat{N}_{x y} \frac{\partial^{2} w}{\partial x \partial y}+\frac{1}{\alpha^{2}} \hat{N}_{y y} \frac{\partial^{2} w}{\partial y^{2}}\right\} \\
& +12 \alpha_{1}^{2}\left\{\frac{\partial u}{\partial x}\left(\frac{\partial^{2} w}{\partial x^{2}}+\frac{v}{\alpha^{2}} \frac{\partial^{2} w}{\partial y^{2}}\right)+\frac{1}{\alpha} \frac{\partial v}{\partial y}\left(v \frac{\partial^{2} w}{\partial x^{2}}+\frac{1}{\alpha^{2}} \frac{\partial^{2} w}{\partial y^{2}}\right)+(1-v)\left(\frac{1}{\alpha} \frac{\partial u}{\partial y}+\frac{\partial v}{\partial x}\right) \frac{1}{\alpha} \frac{\partial^{2} w}{\partial x \partial y}\right\} \\
& +12 \alpha_{1}^{2}\left\{\begin{array}{l}
\frac{1}{2}\left(\frac{\partial w}{\partial x}\right)^{2}\left(\frac{\partial^{2} w}{\partial x^{2}}+v \frac{\partial^{2} w}{\partial y^{2}}\right)+\left(\frac{\partial w}{\partial x} \frac{\partial w_{0}}{\partial x}\right)\left(\frac{\partial^{2} w}{\partial x^{2}}+v \frac{\partial^{2} w}{\partial y^{2}}\right)+\frac{1}{2 \alpha^{2}}\left(\frac{\partial w}{\partial y}\right)^{2}\left(v \frac{\partial^{2} w}{\partial x^{2}}+\frac{1}{\alpha^{2}} \frac{\partial^{2} w}{\partial y^{2}}\right) \\
+\frac{1}{2 \alpha^{2}}\left(\frac{\partial w}{\partial y} \frac{\partial w_{0}}{\partial y}\right)\left(v \frac{\partial^{2} w}{\partial x^{2}}+\frac{1}{\alpha^{2}} \frac{\partial^{2} w}{\partial y^{2}}\right)+\frac{(1-v)}{\alpha^{2}}\left(\frac{\partial w}{\partial x} \frac{\partial w}{\partial y} \frac{\partial^{2} w}{\partial x \partial y}+\frac{\partial w_{0}}{\partial x} \frac{\partial w}{\partial y} \frac{\partial^{2} w}{\partial x \partial y}+\frac{\partial w}{\partial x} \frac{\partial w_{0}}{\partial y} \frac{\partial^{2} w}{\partial x \partial y}\right)
\end{array}\right\} \\
& +12 \alpha_{1}^{2}\left\{\frac{\partial u}{\partial x}\left(\frac{\partial^{2} w_{0}}{\partial x^{2}}+\frac{v}{\alpha^{2}} \frac{\partial^{2} w_{0}}{\partial y^{2}}\right)+\frac{1}{\alpha} \frac{\partial v}{\partial y}\left(v \frac{\partial^{2} w_{0}}{\partial x^{2}}+\frac{1}{\alpha^{2}} \frac{\partial^{2} w_{0}}{\partial y^{2}}\right)+(1-v)\left(\frac{1}{\alpha} \frac{\partial u}{\partial y}+\frac{\partial v}{\partial x}\right) \frac{1}{\alpha} \frac{\partial^{2} w_{0}}{\partial x \partial y}\right\} \\
& +12 \alpha_{1}^{2}\left\{\begin{array}{l}
\frac{1}{2}\left(\frac{\partial w}{\partial x}\right)^{2}\left(\frac{\partial^{2} w_{0}}{\partial x^{2}}+v \frac{\partial^{2} w_{0}}{\partial y^{2}}\right)+\left(\frac{\partial w}{\partial x} \frac{\partial w_{0}}{\partial x}\right)\left(\frac{\partial^{2} w_{0}}{\partial x^{2}}+v \frac{\partial^{2} w_{0}}{\partial y^{2}}\right)+\frac{1}{2 \alpha^{2}}\left(\frac{\partial w}{\partial y}\right)^{2}\left(v \frac{\partial^{2} w_{0}}{\partial x^{2}}+\frac{1}{\alpha^{2}} \frac{\partial^{2} w_{0}}{\partial y^{2}}\right) \\
+\frac{1}{2 \alpha^{2}}\left(\frac{\partial w}{\partial y} \frac{\partial w_{0}}{\partial y}\right)\left(v \frac{\partial^{2} w_{0}}{\partial x^{2}}+\frac{1}{\alpha^{2}} \frac{\partial^{2} w_{0}}{\partial y^{2}}\right)+\frac{(1-v)}{\alpha^{2}}\left(\frac{\partial w}{\partial x} \frac{\partial w}{\partial y} \frac{\partial^{2} w_{0}}{\partial x \partial y}+\frac{\partial w_{0}}{\partial x} \frac{\partial w}{\partial y} \frac{\partial^{2} w_{0}}{\partial x \partial y}+\frac{\partial w}{\partial x} \frac{\partial w_{0}}{\partial y} \frac{\partial^{2} w_{0}}{\partial x \partial y}\right)
\end{array}\right\}
\end{aligned}
$$


The boundary conditions for the non-dimensional equations are

clamped edges at $x=0$ and $x=1$

$$
\begin{aligned}
& u=0 \\
& v=0 \\
& w=0 \\
& \frac{\partial w}{\partial x}=0
\end{aligned}
$$

free edges at $y=0$ and $y=1$

$$
\begin{aligned}
& \frac{\partial v}{\partial y}+\alpha v \frac{\partial u}{\partial x}+\frac{1}{2}\left[\frac{1}{\alpha}\left(\frac{\partial w}{\partial y}\right)^{2}+\alpha v\left(\frac{\partial w}{\partial x}\right)^{2}\right]=0 \\
& \frac{\partial u}{\partial y}+\alpha \frac{\partial v}{\partial x}+\frac{\partial w}{\partial x} \frac{\partial w}{\partial y}=0 \\
& \frac{\partial^{2} w}{\partial y^{2}}+\alpha^{2} v \frac{\partial^{2} w}{\partial x^{2}}=0 \\
& \frac{\partial^{3} w}{\partial y^{3}}+\alpha^{2}(2-v) \frac{\partial^{3} w}{\partial y \partial x^{2}}=0
\end{aligned}
$$

The parameters appearing in equations (13)-(23) are

$$
\alpha=\frac{b}{a}, \quad \alpha_{0}=\frac{a}{h}, \quad \alpha_{1}=\frac{d}{h}, \quad \alpha_{2}=\frac{6\left(1-v^{2}\right)}{E h^{3} g^{3}} \varepsilon a^{4}, c=\frac{\hat{c} a^{4}}{T D} \text { and } \hat{N}_{i j}=\frac{\left(1-v^{2}\right)}{E h} N_{i j}
$$

where $T=\sqrt{\frac{\rho a^{4}}{D}}$ is the characteristic time scale and $D=\frac{E h^{3}}{12\left(1-v^{2}\right)}$ is the flexural rigidity of the plate. 


\section{Reduced Order Model (ROM)}

This approach follows the method outlined in $[9,31,37]$. In this approach, the out-of-plane deflection $w$ is expressed as

$$
w=\sum_{i=1}^{m} q_{i}(t) \phi_{i}(x, y)
$$

where $\phi_{i}(x, y)$ are out-of-plane modeshapes of the flat plate obtained by solving the linear eigenvalue problem and $q_{i}(t)$ are the corresponding unknown time dependent coefficients. One should note that the initial imperfection $w_{0}$ is a constant quantity and does not need expansion like the out-of-plane deflection $w$. Substituting equation (25) into equations (13) and (14) we obtain the following equations:

$$
\begin{aligned}
& \frac{\partial^{2} u}{\partial x^{2}}+\frac{(1+v)}{2 \alpha} \frac{\partial^{2} v}{\partial x \partial y}+\frac{(1-v)}{2 \alpha^{2}} \frac{\partial^{2} u}{\partial y^{2}}+\sum_{k, l} q_{k} q_{l}\left[\left(\frac{\partial \phi_{k}}{\partial x} \frac{\partial^{2} \phi_{l}}{\partial x^{2}}+\frac{(1+v)}{2 \alpha^{2}} \frac{\partial \phi_{k}}{\partial y} \frac{\partial^{2} \phi_{l}}{\partial x \partial y}\right)+\frac{(1-v)}{2 \alpha^{2}}\left(\frac{\partial \phi_{k}}{\partial x} \frac{\partial^{2} \phi_{l}}{\partial y^{2}}\right)\right] \\
& +\sum_{k} q_{k}\left[\begin{array}{l}
\left\{\left(\frac{\partial w_{0}}{\partial x} \frac{\partial^{2} \phi_{k}}{\partial x^{2}}+\frac{(1+v)}{2 \alpha^{2}} \frac{\partial w_{0}}{\partial y} \frac{\partial^{2} \phi_{k}}{\partial x \partial y}\right)+\frac{(1-v)}{2 \alpha^{2}}\left(\frac{\partial w_{0}}{\partial x} \frac{\partial^{2} \phi_{k}}{\partial y^{2}}\right)\right\} \\
\left.+\left\{\left(\frac{\partial \phi_{k}}{\partial x} \frac{\partial^{2} w_{0}}{\partial x^{2}}+\frac{(1+v)}{2 \alpha^{2}} \frac{\partial \phi_{k}}{\partial y} \frac{\partial^{2} w_{0}}{\partial x \partial y}\right)+\frac{(1-v)}{2 \alpha^{2}}\left(\frac{\partial \phi_{k}}{\partial x} \frac{\partial^{2} w_{0}}{\partial y^{2}}\right)\right\}\right]=0
\end{array}\right]= \\
& \frac{\partial^{2} v}{\partial y^{2}}+\frac{(1+v) \alpha}{2} \frac{\partial^{2} u}{\partial x \partial y}+\frac{(1-v) \alpha^{2}}{2} \frac{\partial^{2} v}{\partial x^{2}}+\sum_{k, l} q_{k} q_{l}\left[\left(\frac{1}{\alpha} \frac{\partial \phi_{k}}{\partial y} \frac{\partial^{2} \phi_{l}}{\partial y^{2}}+\frac{(1+v) \alpha}{2} \frac{\partial \phi_{k}}{\partial x} \frac{\partial^{2} \phi_{l}}{\partial x \partial y}\right)+\frac{(1-v)}{2}\left(\frac{\partial \phi_{k}}{\partial y} \frac{\partial^{2} \phi_{l}}{\partial x^{2}}\right)\right]
\end{aligned}
$$

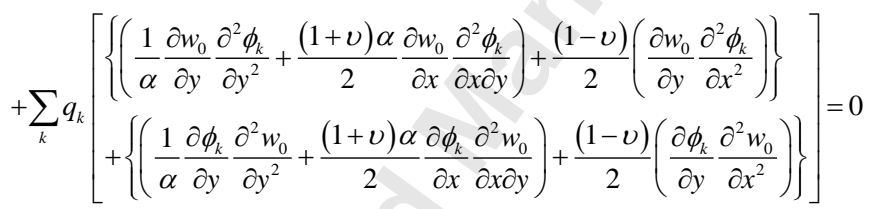

Equations (26) and (27) are nonhomogeneous coupled linear PDEs in $u$ and $v$. Since these equations are linear, the principle of superposition can be used to determine the solution for $u$ and $v$ in the form [37]

$$
\begin{gathered}
u=\sum_{k, l} q_{k} q_{l} u^{k l}+\sum_{k} q_{k} u^{k} \\
v=\sum_{k, l} q_{k} q_{l} v^{k l}+\sum_{k} q_{k} v^{k}
\end{gathered}
$$


where the superscript $k l$ denotes the in-plane displacements $u^{k l}$ and $v^{k l}$ caused by the loads $f_{x}^{k l}$ and $f_{y}^{k l}$ defined as

$$
\begin{gathered}
f_{x}^{k l}=\left(\frac{\partial \phi_{k}}{\partial x} \frac{\partial^{2} \phi_{l}}{\partial x^{2}}+\frac{(1+v)}{2 \alpha^{2}} \frac{\partial \phi_{k}}{\partial y} \frac{\partial^{2} \phi_{l}}{\partial x \partial y}\right)+\frac{(1-v)}{2 \alpha^{2}}\left(\frac{\partial \phi_{k}}{\partial x} \frac{\partial^{2} \phi_{l}}{\partial y^{2}}\right) \\
f_{y}^{k l}=\left(\frac{1}{\alpha} \frac{\partial \phi_{k}}{\partial y} \frac{\partial^{2} \phi_{l}}{\partial y^{2}}+\frac{(1+v) \alpha}{2} \frac{\partial \phi_{k}}{\partial x} \frac{\partial^{2} \phi_{l}}{\partial x \partial y}\right)+\frac{(1-v)}{2}\left(\frac{\partial \phi_{k}}{\partial y} \frac{\partial^{2} \phi_{l}}{\partial x^{2}}\right)
\end{gathered}
$$

and similarly superscript $k$ denotes the in-plane displacements $u^{k}$ and $v^{k}$ caused by the loads $f_{x}^{k}$ and $f_{y}^{k}$ defined as

$$
\begin{aligned}
& f_{x}^{k}=\left[\begin{array}{l}
\left\{\left(\frac{\partial w_{0}}{\partial x} \frac{\partial^{2} \phi_{k}}{\partial x^{2}}+\frac{(1+v)}{2 \alpha^{2}} \frac{\partial w_{0}}{\partial y} \frac{\partial^{2} \phi_{k}}{\partial x \partial y}\right)+\frac{(1-v)}{2 \alpha^{2}}\left(\frac{\partial w_{0}}{\partial x} \frac{\partial^{2} \phi_{k}}{\partial y^{2}}\right)\right\} \\
+\left\{\left(\frac{\partial \phi_{k}}{\partial x} \frac{\partial^{2} w_{0}}{\partial x^{2}}+\frac{(1+v)}{2 \alpha^{2}} \frac{\partial \phi_{k}}{\partial y} \frac{\partial^{2} w_{0}}{\partial x \partial y}\right)+\frac{(1-v)}{2 \alpha^{2}}\left(\frac{\partial \phi_{k}}{\partial x} \frac{\partial^{2} w_{0}}{\partial y^{2}}\right)\right\}
\end{array}\right] \\
& f_{y}^{k}=\left[\begin{array}{l}
\left\{\left(\frac{1}{\alpha} \frac{\partial w_{0}}{\partial y} \frac{\partial^{2} \phi_{k}}{\partial y^{2}}+\frac{(1+v) \alpha}{2} \frac{\partial w_{0}}{\partial x} \frac{\partial^{2} \phi_{k}}{\partial x \partial y}\right)+\frac{(1-v)}{2}\left(\frac{\partial w_{0}}{\partial y} \frac{\partial^{2} \phi_{k}}{\partial x^{2}}\right)\right\} \\
+\left\{\left(\frac{1}{\alpha} \frac{\partial \phi_{k}}{\partial y} \frac{\partial^{2} w_{0}}{\partial y^{2}}+\frac{(1+v) \alpha}{2} \frac{\partial \phi_{k}}{\partial x} \frac{\partial^{2} w_{0}}{\partial x \partial y}\right)+\frac{(1-v)}{2}\left(\frac{\partial \phi_{k}}{\partial y} \frac{\partial^{2} w_{0}}{\partial x^{2}}\right)\right\}
\end{array}\right]
\end{aligned}
$$

Equation (15) is multiplied by $(1-w)^{2}$ to treat the electric force term exactly with no approximation. Now by substituting equations (25), (28) and (29) into equation (15), multiplying by $\phi_{i}(x, y)$ and integrating over the plate domain we get the reduced order model. The reduced order model consists of a system of nonlinear coupled ordinary differential equations (ODEs) in $q_{i}(t)$. This system of ODEs is solved for $q_{i}(t)$ numerically using the Runge Kutta method and is substituted back into equation (25), (28) and (29) to obtain $w, u$ and $v$ respectively. In this study we use a three-mode reduced order model, which consists of a system of three nonlinear coupled ODEs. It has been shown that the first three symmetric-symmetric modes are sufficient to get a converged solution [9]. 


\section{Fabrication Process of Microplate}

The fabrication of the MEMS microplate was done using the surface micromachining process at KAUST Advanced Nano Fabrication (ANIC) laboratory. The microplate is a five layer structure, where polyimide is the main structure material, sandwiched in thin layers of nickel on the top and chromium and gold layers on the bottom. The fabrication flow chart is the same as in [14] and a schematic of the microplate cross-section is provided in Figure 2, while material and thickness information of the constituent layers of the microplate is provided in Table 1.

\section{Results}

In the following we present the results, obtained by experiment and the reduced order model.

\section{Experimental results}

An optical interferometry profiler was used to characterize the surface profile of the microplate without the application of any electrostatic load. Profilometry results show that the microplate has acquired a slight initial curvature, which is often due to the residual stresses and stress gradient caused by the micro fabrication process. The orientation of the curvature is such that the microplate is bent away from the stationary electrode. The maximum initial deflection $w_{0}$ at the center of the microplate is recorded to be $w_{0 \max }=0.55 \mu \mathrm{m}$. The dimensional parameters of the microplate are given in Table 2 .

A 3D image of the microplate taken by the optical profilometer is shown in Figure 3a, while a micrograph taken under the microscope is shown in Figure 3b. Curvature profiles of the microplate along the length and the width at the center are shown in Figure $4 \mathrm{a}$ and b, respectively.

The experimental setup used for capturing the responses of the microplate when actuated by electrostatic loads is shown in Figure 5. It consists of the micro system analyzer MSA-500, a vacuum chamber; which houses the microplate, a vacuum pump to reduce the pressure, and a data acquisition system DAQ. 
First, the microplate was actuated by the application of a white noise to identify the linear resonance frequencies of the microplate. Figure 6 shows the linear responses and the corresponding modes of vibration over the scanned window of $1 \mathrm{MHz}$. One can notice that the response near the first resonance frequency is much larger than the responses at higher modes of vibration. Other than the first resonance, responses at second, third, and fourth resonance frequencies and corresponding modes of vibration are also shown.

Next we measure the variation of the first natural frequency with the increase of applied DC voltage. As expected, and due to the softening nature of electrostatic force, Fig. 7 shows that as the applied DC load increases, the natural frequency decreases. This phenomenon has been investigated theoretically [29, 31]. Such results are useful for the parameter extraction of the studied microplate.

To capture the forced dynamic responses of the microplate, an AC load superimposed to a DC load is applied and frequency sweeps around the fundamental resonance frequency are performed. Linear dynamic response is captured while a small AC load is applied. To capture the nonlinear response, we increase the harmonic AC load while the DC load is kept constant. Figure 8 shows the frequency sweep curves in the neighborhood of the fundamental resonance frequency for various values of AC load while the $\mathrm{DC}$ load was fixed at $2 \mathrm{~V}$. One can see that for small value of $\mathrm{AC}$ load at $1 \mathrm{~V}$ the response is clearly linear, while when the AC load is increased to $3 \mathrm{~V}$, the microplate shows a nonlinear hardening response.

Figure 9 shows the dynamic pull-in instability of the microplate. Near the nonlinear resonance frequency, the amplitude of vibration is quite large that the electrostatic force overcomes the elastic restoring force and the microplate collapses over the stationary electrode. One can note that the dynamic pull-in instability is characterized by a slope approaching infinity [38]. Dynamic pull-in occurs when dynamic 
inertial forces contribute to the collapse of flexible plate. It usually occurs at much lower voltage load compared to the static pull-in voltage.

It is reported $[30,39]$ that upon the application of high DC loads, initially hardening behavior of microplates can be converted to softening behavior. This phenomenon is depicted in Figure 10 by plotting frequency response curves in the neighborhood of primary resonance. The microplate was actuated by various DC loads in the increasing order while an AC load was fixed at a small $0.5 \mathrm{~V}$. The figure shows a clear softening behavior at a DC load of $12 \mathrm{~V}$. To capture the complete upper stable branch and hysteresis [39], we performed both forward and backward frequency sweeps in Figure 11. The microplate shows coexistence of two stable solutions over a long range of frequency.

\section{Theoretical Results}

Here we calculate the theoretical results using the reduced order model presented in Section 3 and compare them with the experimental data for the validation purpose. Since the microplate is made up of several layers of different materials, we calculate an equivalent flexural rigidity to be used in the model. The expression of flexural rigidity, $D$ of the plate can be written as

$$
D=\frac{E h^{3}}{12\left(1-v^{2}\right)}=\frac{E I}{b\left(1-v^{2}\right)}=\frac{d}{\left(1-v^{2}\right)}
$$

where $I=\frac{b h^{3}}{12}$ is the second moment of area about the centroidal axis and $d=\frac{E I}{b}$. Now equivalent $d$ $\left(d_{e q}\right)$ for the microplate can be calculated as [15]

$$
d_{e q}=\frac{1}{b}\left(E_{1} I_{1}+E_{2} I_{2}+E_{3} I_{3}+E_{4} I_{4}+E_{5} I_{5}\right)
$$

where the subscript refers to the layer number. The second moment of area about the centroidal axis of the microplate for each layer can be calculated using parallel axes theorem using the expression 


$$
I_{i}=\frac{b t_{i}^{3}}{12}+b t_{i} d_{i}^{2}
$$

where $t_{i}$ is the thickness and $d_{i}$ is the perpendicular distance between the centroidal axis of the $i^{\text {th }}$ layer and the microplate. Perpendicular distance between the centroidal axis of the layer and the microplate is given in Table 3 for each layer. Material parameters used in this analysis are given in Table 4. By plugging the $E$ and $I$ values in the formula for $d_{e q}$, we find that $d_{e q}=885 \times 10^{-9} \mathrm{~N}-\mathrm{m}$. An equivalent density of the microplate can be calculated as $\rho_{e q}=\frac{1}{h}\left(\rho_{1} t_{1}+\rho_{2} t_{2}+\rho_{3} t_{3}+\rho_{4} t_{4}+\rho_{5} t_{5}\right)$ and is found to be $3020 \mathrm{Kg} / \mathrm{m}^{3}$.

The initial imperfection curvature profiles of the microplate along the length and width are approximated by the geometric functions $\left\{1-\operatorname{Cos}^{16}(\pi x)\right\}$ and $\operatorname{Sin}(\pi y)$, respectively. Figure 12 shows the experimentally measured and approximated curvature profiles along the length and width at the center of the microplate. The microplate was placed horizontally in $x y$ plane and initial deflection $w_{0}$ is measured along vertical $z$ axis.

We compare the simulation results obtained from the reduced order model with the experimental results in the neighborhood of primary resonance. The quality factor $Q$ is approximated by matching the theoretical responses from the reduced order model with the experimental data in the linear dynamic range. An in-plane compressive load $N_{x x}=-54.5 \mathrm{~N} / \mathrm{m}$ along the longitudinal axis is applied to compensate for the axial residual stress from fabrication and to match the experimentally measured linear natural frequency. Figure 13 shows the comparison of the simulation results with the experimentally measured responses when the microplate is actuated by a small harmonic AC load superimposed to a DC load. A quality factor $Q=480$ gives an excellent match of the theoretical and experimental results.

Next we actuate the microplate by a large AC load, which induces the nonlinear dynamic behavior. In Figure 14, we compare the nonlinear dynamic responses obtained by the reduced order model with similar 
responses measured experimentally. The comparison shows an excellent agreement with the experimental results thus validating the model.

Nest, we examine the effect of the initial curvature of the plate. We investigate the variation of the natural frequencies of the first three symmetric-symmetric modes of vibration with the maximum initial rise $w_{0}$ of the curvature imperfection of the plate. For the calculation of the natural frequencies, we drop the electrostatic forcing and nonlinear terms and solve the linear eigenvalue problem using the reduced order model outlined in Section 3.

Figure 15 show variation of the non-dimensional natural frequencies of the first three symmetricsymmetric modes against the normalized maximum initial rise of the curvature imperfection. We note that first natural frequency increases with the increase of initial curvature rise reaching a maximum of 26 at $w_{0 \max } / h=0.38$ and then starts decreasing with the further increase of curvature rise. The second and third modes, contrary to the first mode show a steady increase of the respective natural frequencies. This investigation is based on the curvature profile considered in this study and is without consideration of any pre-stress. It is worth mentioning that depending on the curvature profile and initial rise of the curvature, plate behavior can show drastic changes. Natural frequencies can be significantly influenced $[20,40]$ and dynamic behavior may be converted from a hardening to softening one [20, 25, 41].

\section{Summary and Conclusions}

In this article we have presented experimental and theoretical investigation of the dynamic behavior of an initially curved multilayer microplate under electrostatic actuation. The microplate is bent away from the electrostatic electrode contrary to the previous work in [9]. This paper completes the mechanical behavior understanding of initially imperfect microplates and also provides extensive experimental data along with accurate modeling of the equivalent flexural rigidity of the multiple material layers of the. First, we 
analyzed the microplate under white noise to identify the resonances and modes shapes of the microplate. Then the variation of fundamental natural frequency of the microplate under DC load was captured.

Next, the forced dynamic responses were captured under small and large harmonic AC loads. Under the large harmonic AC load, the midplane stretching nonlinearity is activated and the microplate shows a nonlinear hardening behavior. It is also depicted experimentally that at large DC loads the microplate shows a softening behavior, which has been investigated theoretically.

To simulate the behavior of the microplate under small and large actuating forces, we used three mode reduced order model based on the dynamic analogue of von-Karman equations, which accounts for the initial curvature imperfection. Since the model is based on isotropic material, we calculated an equivalent flexural rigidity and density to be used in the model. Simulation results show excellent agreement with the experimentally measured results, thus validating the model. Further we investigated variation of the natural frequencies of the modes against the initial rise of the curvature. The first natural frequency increases first with the initial rise to achieve a maximum before it starts decreasing, while the natural frequencies of the higher modes show a steady increase.

\section{References}

1. Tong, P. and Huang, W., 2002,"Large Deflection of Thin Plates in Pressure Sensor Applications,"Journal of Applied Mechanics, 69(6), pp. 785-789.

2. Roman, M. and Aubry, N., 2003, Design and Fabrication of Electrostatically Actuated Synthetic Microjets. in ASME 2003 International Mechanical Engineering Congress and Exposition. American Society of Mechanical Engineers.

3. Ng, T.Y., Jiang, T.Y., Li, H., Lam, K.Y., and Reddy, J.N., 2004,"A Coupled Field Study on the NonLinear Dynamic Characteristics of an Electrostatic Micropump,"Journal of Sound and Vibration, 273(4-5), pp. 989-1006.

4. Machauf, A., Nemirovsky, Y., and Dinnar, U., 2005,"A Membrane Micropump Electrostatically Actuated across the Working Fluid,"Journal of Micromechanics and Microengineering, 15(12), pp. 2309-2316.

5. Horowitz, S., Nishida, T., Cattafesta, L., and Sheplak, M., 2007,"Development of a Micromachined Piezoelectric Microphone for Aeroacoustics Applications,"The Journal of the Acoustical Society of America, 122(6), pp. 3428-3436.

6. Amirouche, F., Zhou, Y., and Johnson, T., 2009,"Current Micropump Technologies and Their Biomedical Applications,"Microsystem Technologies, 15(5), pp. 647-666. 
7. Faris, W.F., Abdel-Rahman, E.M., and Nayfeh, A.H., 2002-1303, Mechanical Behavior of an Electrostatically Actuated Micropump. in 43 rd AIAA/ASME/ASCE/AHS/ASC Structures, Structural Dynamics, and Materials Conference, Denver, $C O$.

8. Medina, L., Gilat, R., Ilic, B., and Krylov, S., 2014,"Experimental Investigation of the Snap-through Buckling of Electrostatically Actuated Initially Curved Pre-Stressed Micro Beams," Sensors and Actuators A: Physical, 220(pp. 323-332.

9. Saghir, S., Bellaredj, M., Ramini, A., and Younis, M., 2016,"Initially Curved Microplates under Electrostatic Actuation: Theory and Experiment,"Journal of Micromechanics and Microengineering, 26(9), pp. 095004.

10. Farokhi, H., Ghayesh, M.H., and Amabili, M., 2013,"Nonlinear Dynamics of a Geometrically Imperfect Microbeam Based on the Modified Couple Stress Theory,"International Journal of Engineering Science, 68(pp. 11-23.

11. Medina, L., Gilat, R., and Krylov, S., 2016,"Bistable Behavior of Electrostatically Actuated Initially Curved Micro Plate,"Sensors and Actuators A: Physical, 248(pp. 193-198.

12. Krylov, S. and Dick, N., 2010,"Dynamic Stability of Electrostatically Actuated Initially Curved Shallow Micro Beams,"Continuum Mechanics and Thermodynamics, 22(6-8), pp. 445-468.

13. Alijani, F. and Amabili, M., 2013,"Theory and Experiments for Nonlinear Vibrations of Imperfect Rectangular Plates with Free Edges,"Journal of Sound and Vibration, 332(14), pp. 3564-3588.

14. Ilyas, S., Arevalo, A., Bayes, E., Foulds, I.G., and Younis, M.I., 2015,"Torsion Based Universal Mems Logic Device,"Sensors and Actuators A: Physical, 236(pp. 150-158.

15. Petras, A., Design of Sandwich Structures. 1999, University of Cambridge.

16. Krylov, S., llic, B.R., Schreiber, D., Seretensky, S., and Craighead, H., 2008,"The Pull-in Behavior of Electrostatically Actuated Bistable Microstructures, "Journal of Micromechanics and Microengineering, 18(5), pp. 055026.

17. Ouakad, H.M. and Younis, M.I., 2010,"The Dynamic Behavior of Mems Arch Resonators Actuated Electrically,"International Journal of Non-Linear Mechanics, 45(7), pp. 704-713.

18. Ruzziconi, L., Bataineh, A.M., Younis, M.I., Cui, W., and Lenci, S., 2013,"Nonlinear Dynamics of an Electrically Actuated Imperfect Microbeam Resonator: Experimental Investigation and ReducedOrder Modeling,"Journal of micromechanics and microengineering, 23(7), pp. 075012.

19. Jaber, N., Ramini, A., Carreno, A.A., and Younis, M.I., 2016,"Higher Order Modes Excitation of Electrostatically Actuated Clamped-Clamped Microbeams: Experimental and Analytical Investigation,"Journal of Micromechanics and Microengineering, 26(2), pp. 025008.

20. Celep, Z., 1976,"Free Flexural Vibration of Initially Imperfect Thin Plates with Large Elastic Amplitudes,"ZAMM-Journal of Applied Mathematics and Mechanics/Zeitschrift für Angewandte Mathematik und Mechanik, 56(9), pp. 423-428.

21. Celep, Z., 1980,"Shear and Rotatory Inertia Effects on the Large Amplitude Vibration of the Initially Imperfect Plates,"Journal of Applied Mechanics, 47(3), pp. 662-666.

22. Yamaki, N. and Chiba, M., 1983,"Nonlinear Vibrations of a Clamped Rectangular Plate with Initial Deflection and Initial Edge Displacement-Part I: Theory,"Thin-Walled Structures, 1(1), pp. 3-29.

23. Yamaki, N., Otomo, K., and Chiba, M., 1983,"Nonlinear Vibrations of a Clamped Rectangular Plate with Initial Deflection and Initial Edge Displacement-Part li: Experiment,"Thin-Walled Structures, 1(2), pp. 101-119.

24. Marín, J., Perkins, N.C., and Vorus, W., 1994,"Non-Linear Response of Predeformed Plates Subject to Harmonic in-Plane Edge Loading,"Journal of Sound and vibration, 176(4), pp. 515-529.

25. Lin, C. and Chen, L., 1989,"Large-Amplitude Vibration of an Initially Imperfect Moderately Thick Plate,"Journal of Sound and Vibration, 135(2), pp. 213-224.

26. Ostiguy, G.L. and Sassi, S., 1992,"Effects of Initial Geometric Imperfections on Dynamic Behavior of Rectangular Plates,"Nonlinear Dynamics, 3(3), pp. 165-181. 
27. Chao, P.C., Chiu, C.-W., and Tsai, C., 2006,"A Novel Method to Predict the Pull-in Voltage in a Closed Form for Micro-Plates Actuated by a Distributed Electrostatic Force,"Journal of Micromechanics and microengineering, 16(5), pp. 986-998.

28. Vogl, G.W. and Nayfeh, A.H., 2003, A Reduced-Order Model for Electrically Actuated Clamped Circular Plates. in ASME 2003 International Design Engineering Technical Conferences and Computers and Information in Engineering Conference. American Society of Mechanical Engineers.

29. Zhao, X., Abdel-Rahman, E.M., and Nayfeh, A.H., 2004,"A Reduced-Order Model for Electrically Actuated Microplates,"Journal of Micromechanics and Microengineering, 14(7), pp. 900-906.

30. Saghir, S. and Younis, M.I., 2016,"An Investigation of the Static and Dynamic Behavior of Electrically Actuated Rectangular Microplates,"International Journal of Non-Linear Mechanics, 85(pp. 81-93.

31. Saghir, S. and Younis, M.I., 2017,"Approaches for Reduced-Order Modeling of Electrically Actuated Von-Karman Microplates,"Journal of Computational and Nonlinear Dynamics, 12(1), pp. 011011.

32. Batra, R.C., Porfiri, M., and Spinello, D., 2007,"Review of Modeling Electrostatically Actuated Microelectromechanical Systems,"Smart Materials and Structures, 16(6), pp. R23.

33. Batra, R.C., Porfiri, M., and Spinello, D., 2008,"Reduced-Order Models for Microelectromechanical Rectangular and Circular Plates Incorporating the Casimir Force,"International Journal of Solids and Structures, 45(11-12), pp. 3558-3583.

34. Wang, B., Zhou, S., Zhao, J., and Chen, X., 2011,"Pull-in Instability Analysis of Electrostatically Actuated Microplate with Rectangular Shape,"International Journal of Precision Engineering and Manufacturing, 12(6), pp. 1085-1094.

35. Vogl, G.W. and Nayfeh, A.H., 2005,"A Reduced-Order Model for Electrically Actuated Clamped Circular Plates,"Journal of Micromechanics and Microengineering, 15(4), pp. 684-690.

36. Chen, C.S., Cheng, W.S., and Tan, A.H., 2005,"Non-Linear Vibration of Initially Stressed Plates with Initial Imperfections,"Thin-Walled Structures, 43(1), pp. 33-45.

37. Lobitz, D., Nayfeh, A., and Mook, D., 1977,"Non-Linear Analysis of Vibrations of Irregular Plates,"Journal of Sound and Vibration, 50(2), pp. 203-217.

38. Nayfeh, A.H. and Younis, M.I., 2005,"Dynamics of Mems Resonators under Superharmonic and Subharmonic Excitations,"Journal of Micromechanics and Microengineering, 15(10), pp. 1840.

39. Younis, M.I., Mems Linear and Nonlinear Statics and Dynamics. Vol. 20. 2011: Springer.

40. Liu, W. and Yeh, F., 1993,"Non-Linear Vibrations of Initially Imperfect, Orthotropic, Moderately Thick Plates with Edge Restraints,"Journal of sound and vibration, 165(1), pp. 101-122.

41. Amabili, M., 2006,"Theory and Experiments for Large-Amplitude Vibrations of Rectangular Plates with Geometric Imperfections,"Journal of Sound and Vibration, 291(3), pp. 539-565. 


\section{Table Captions List}

Table 1: Material and thickness information of the constituent layers of the microplate.

Table 2: Dimensional parameters of the microplate.

Table 3: Perpendicular distance (di) between the centroidal axis of the various layers and the microplate.

Table 4: Material parameters of the various layers of the microplate. 


\section{Figure Captions List}

Figure 1: A schematic diagram of an initially curved clamped-free-clamped-free (CFCF) microplate under electrostatic actuation.

Figure 2: A schematic diagram of a cross-section of the fabricated microplate, showing the material layers.

Figure 3: (a) 3D micrograph constructed by optical profilometer, (b) Top view picture taken under the microscope.

Figure 4: (a) Curvature profile of the microplate along the length at the center. (b) Curvature profile of the microplate along the width at the center.

Figure 5: Experimental setup showing the micro-system analyzer MSA-500, a vacuum chamber, and data acquisition system DAQ.

Figure 6: First four resonance frequencies and modes of vibration of the microplate, captured when excited by a white noise signal of $V_{d c}=3 \mathrm{~V}$ and $V_{a c}=10 \mathrm{~V}$.

Figure 7: (a) Linear response at first resonance when actuated by white noise at various values of DC load. (b) Variation of the first resonance frequency with the DC load.

Figure 8: Linear and nonlinear responses of the microplate when actuated by various harmonic AC loads superimposed to a constant DC load of $2 \mathrm{~V}$ with a step size of $10 \mathrm{~Hz}$ and a chamber pressure of $2.6 \mathrm{mT}$ Torr.

Figure 9: Dynamic pull-in when the microplate is actuated by a $V_{a c}=3 \mathrm{~V}$ and a $V_{d c}=2 \mathrm{~V}$ with a step size of $1 \mathrm{~Hz}$ and a chamber pressure of $2.1 \mathrm{mT}$ Torr. 
Figure 10: Frequency response curves near the primary resonance at various DC loads while an AC load was fixed at $0.5 \mathrm{~V}$, depicting the softening behavior at high DC loads. The step size was $10 \mathrm{~Hz}$ and the chamber pressure was $2.6 \mathrm{mTorr}$.

Figure 11: Forward and backward frequency sweep curves at a $V_{a c}=0.5 \mathrm{~V}$ and a $V_{d c}=12 \mathrm{~V}$. The chamber pressure was fixed at 1.8 mTorr.

Figure 12: Initial curvature imperfection profiles at the center of the microplate; experimentally measured '_-' and approximated '_-', (a) along the length, (b) along the width.

Figure 13: Frequency response plots of the microplate; theory ' + ' and the experiment '*', when actuated by a $V_{a c}=1 \mathrm{~V}$ and $V_{d c}=2 \mathrm{~V}$. A quality factor $Q=480$ was used for simulation.

Figure 14: Frequency response plots of the microplate; theory ' + ' and the experiment '*', when actuated by a $\mathrm{V}_{\mathrm{ac}}=3 \mathrm{~V}$ and $\mathrm{V}_{\mathrm{dc}}=2 \mathrm{~V}$. A quality factor $\mathrm{Q}=480$ was used for simulation.

Figure 15: Variation of the natural frequency of the symmetric-symmetric modes of vibration with the maximum initial rise of the curvature imperfection. (a) First symmetric-symmetric mode. (b) Second symmetric-symmetric mode. (c) Third symmetric-symmetric mode. 


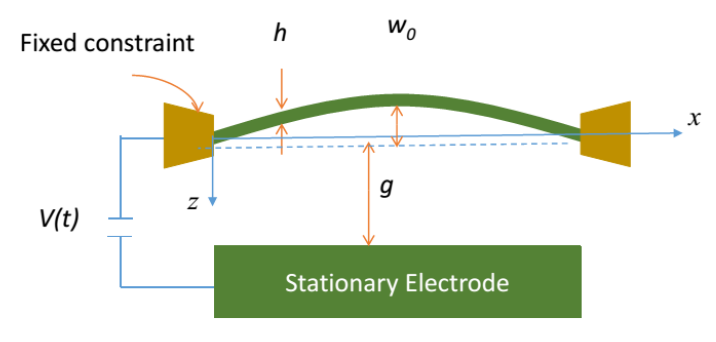

Front View

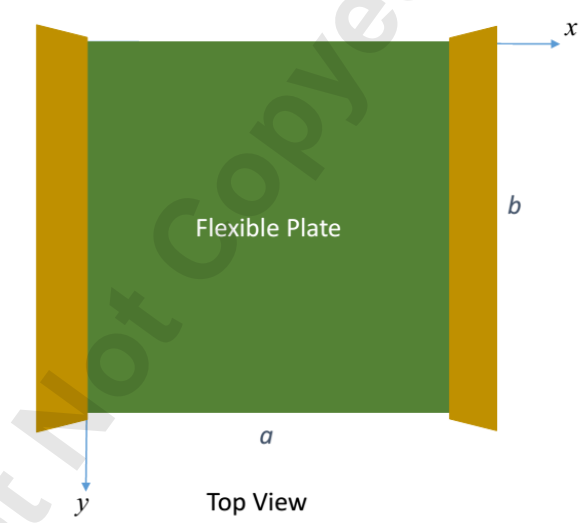

Figure 16: A schematic diagram of an initially curved clamped-free-clamped-free (CFCF) microplate under electrostatic actuation. 
1

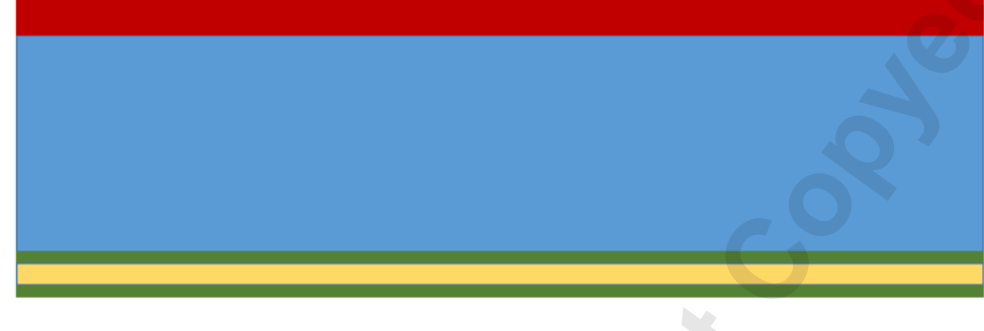

5

Figure 17: A schematic diagram of a cross-section of the fabricated microplate, showing the material layers. 


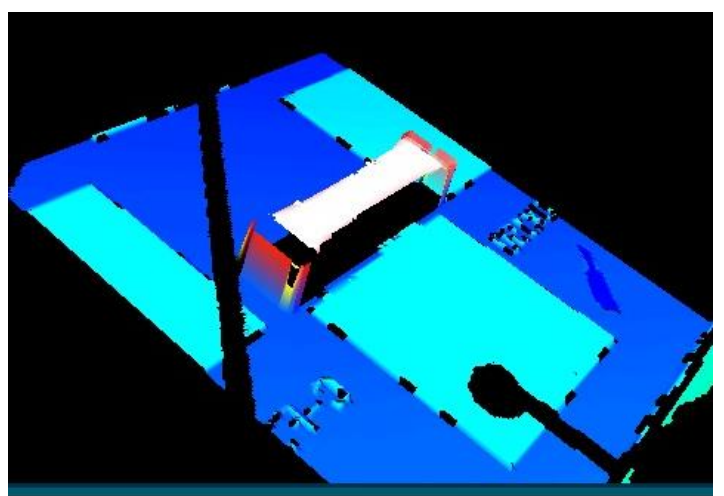

(a)

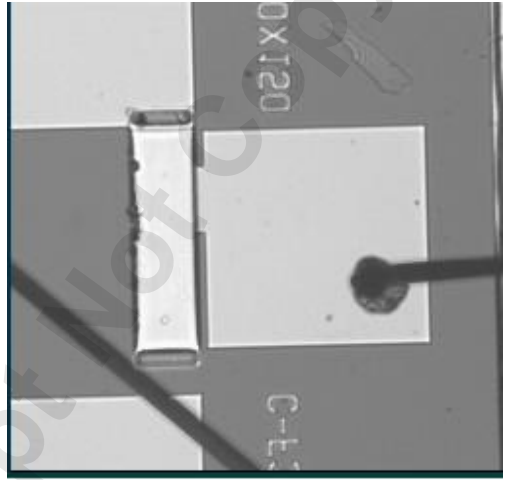

(b)

Figure 18: (a) 3D micrograph constructed by optical profilometer, (b) Top view picture taken under the microscope. 


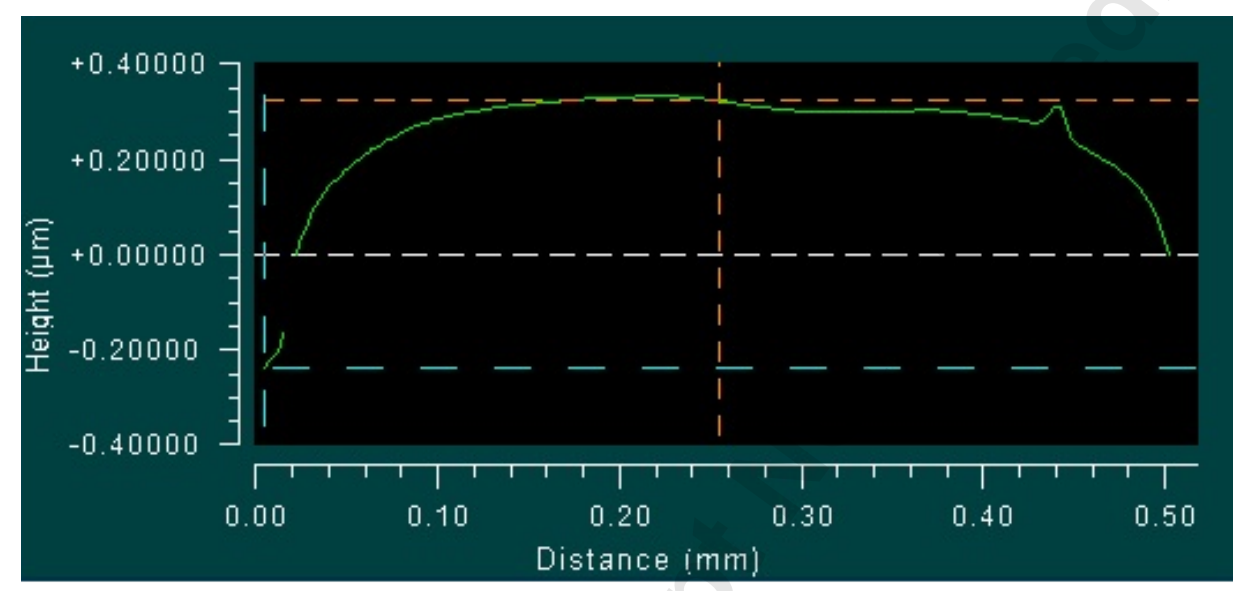

(a)

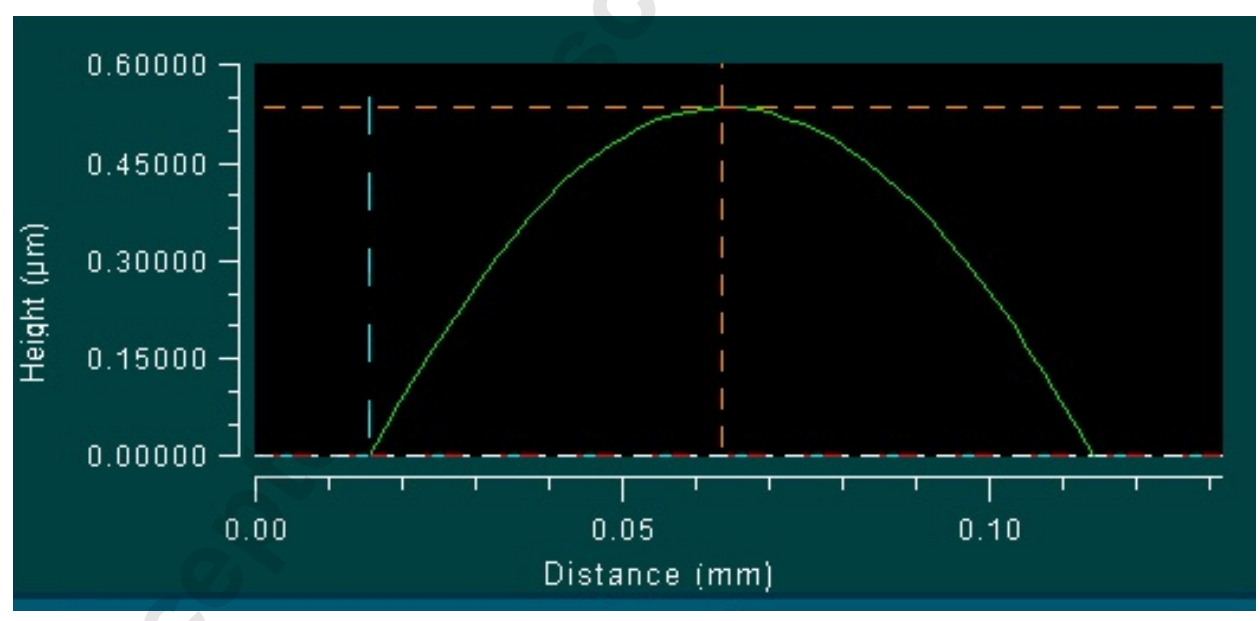

(b)

Figure 19: (a) Curvature profile of the microplate along the length at the center. (b) Curvature profile of the microplate along the width at the center. 


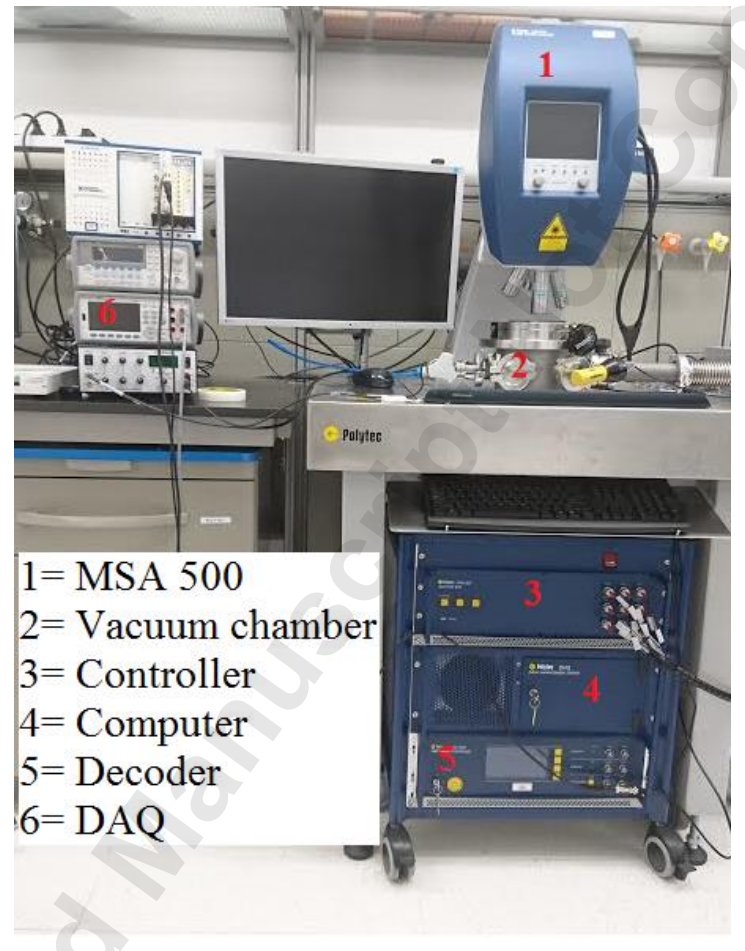

Figure 20: Experimental setup showing the micro-system analyzer MSA-500, a vacuum chamber, and data acquisition system DAQ. 


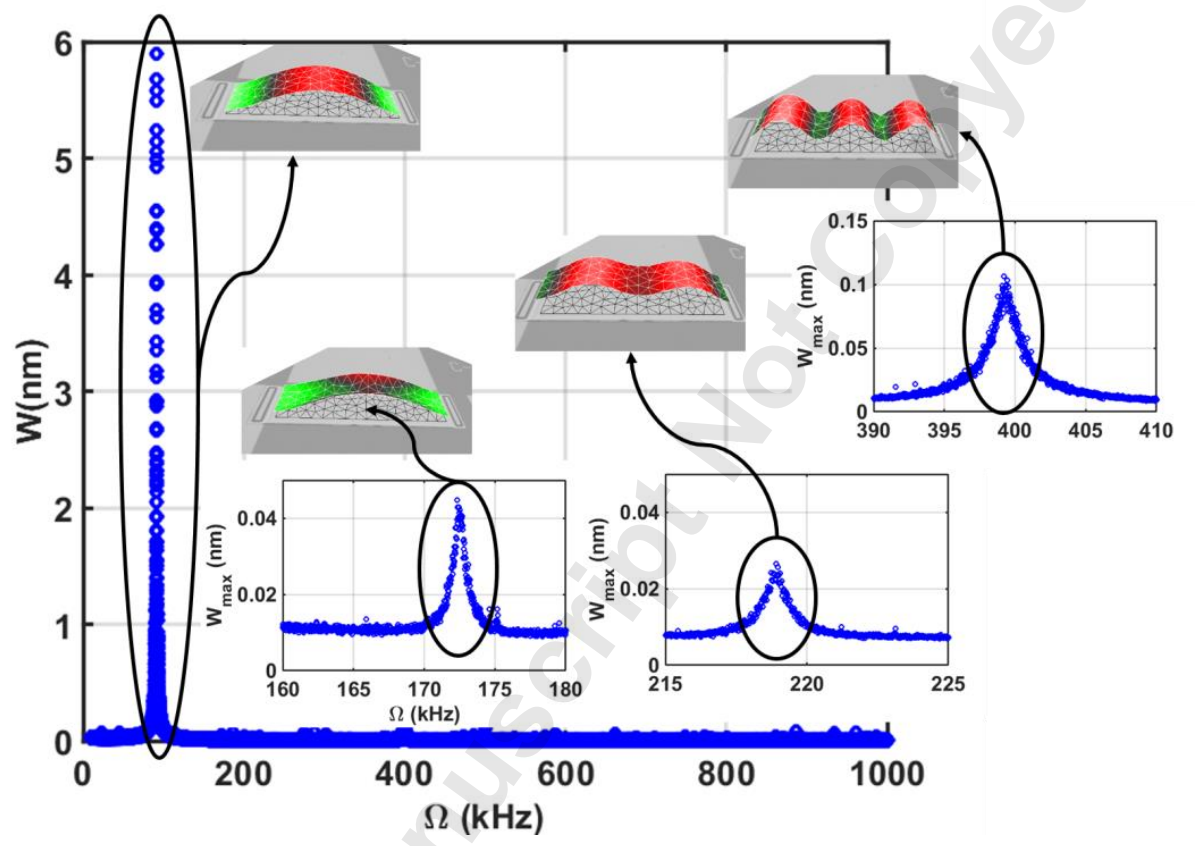

Figure 21: First four resonance frequencies and modes of vibration of the microplate, captured when excited by a white noise signal of $V_{d c}=3 \mathrm{~V}$ and $V_{a c}=10 \mathrm{~V}$. 


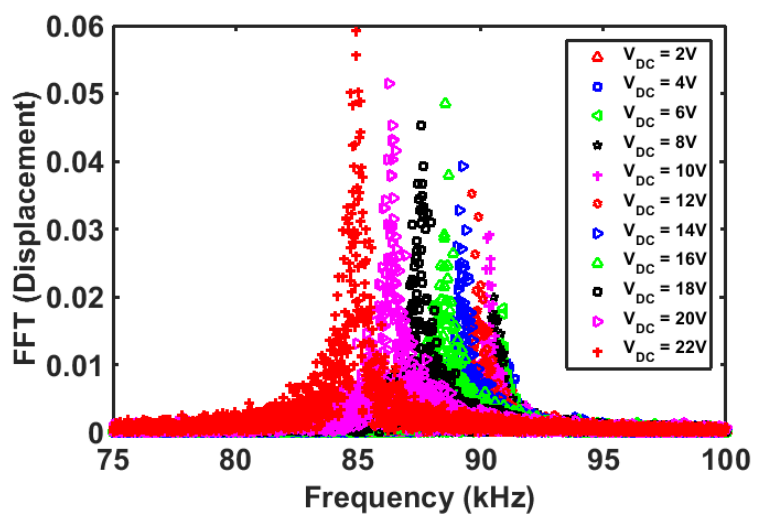

(a)

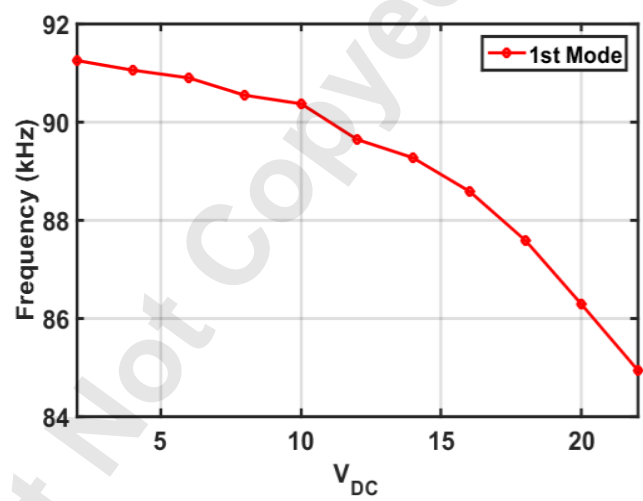

(b)

Figure 22: (a) Linear response at first resonance when actuated by white noise at various values of DC load. (b) Variation of the first resonance frequency with the DC load. 


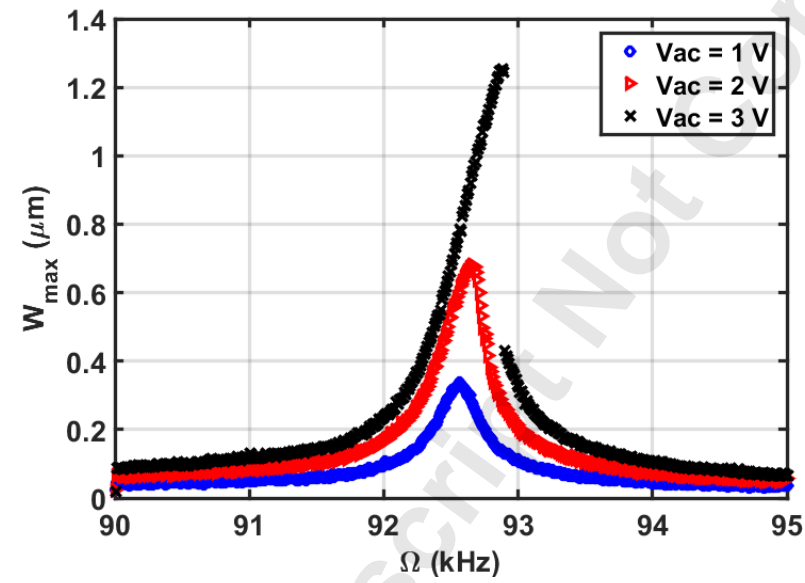

Figure 23: Linear and nonlinear responses of the microplate when actuated by various harmonic AC loads superimposed to a constant DC load of $2 \mathrm{~V}$ with a step size of $10 \mathrm{~Hz}$ and a chamber pressure of $2.6 \mathrm{mT}$ Torr. 


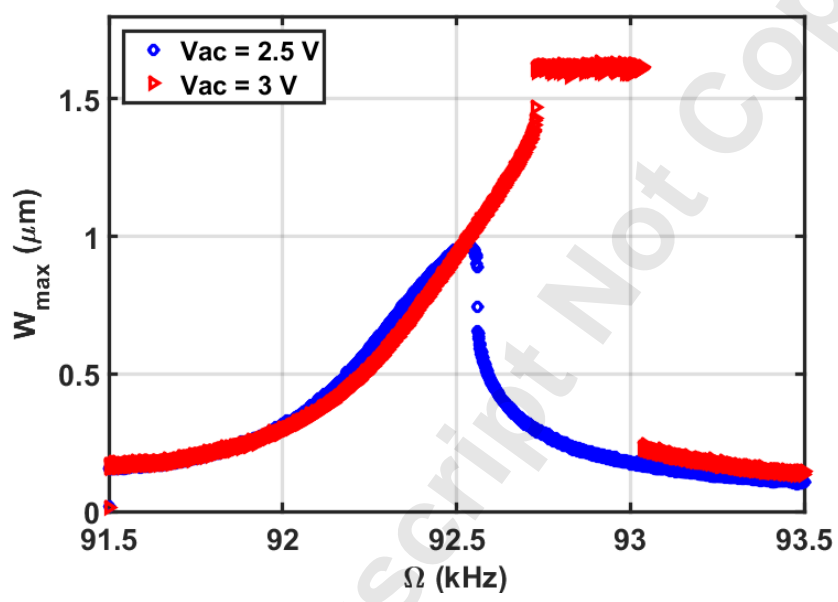

Figure 24: Dynamic pull-in when the microplate is actuated by a $V_{a c}=3 \mathrm{~V}$ and a $V_{d c}=2 \mathrm{~V}$ with a step size of $1 \mathrm{~Hz}$ and a chamber pressure of $2.1 \mathrm{mT}$ Torr. 


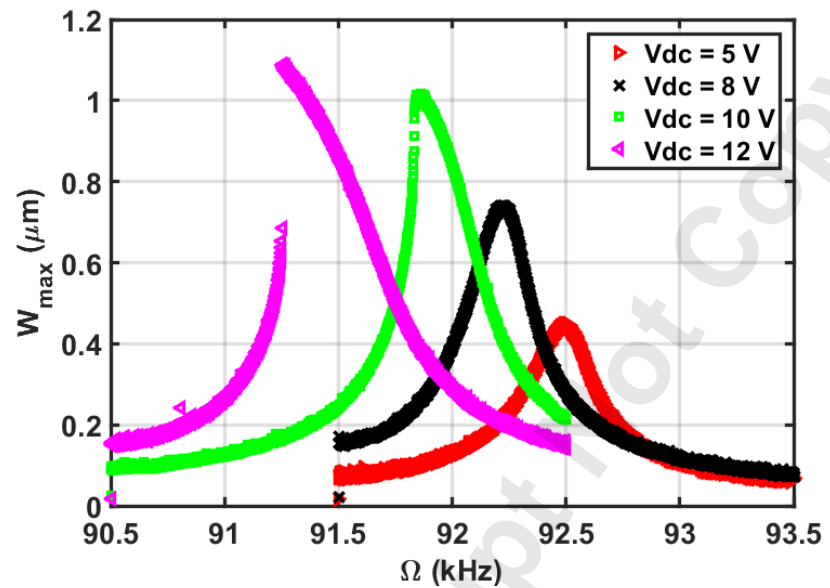

Figure 25: Frequency response curves near the primary resonance at various DC loads while an AC load was fixed at $0.5 \mathrm{~V}$, depicting the softening behavior at high DC loads. The step size was $10 \mathrm{~Hz}$ and the chamber pressure was $2.6 \mathrm{mT}$ Torr. 


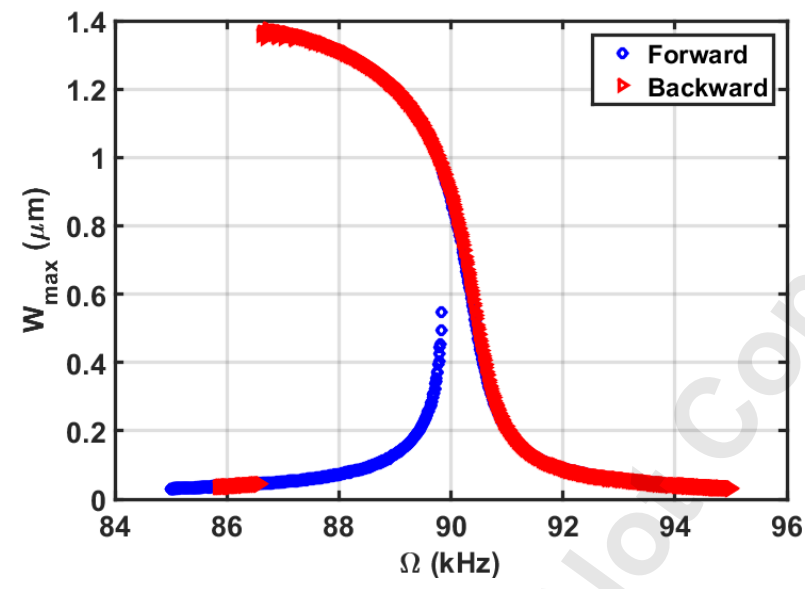

Figure 26: Forward and backward frequency sweep curves at a $V_{a c}=0.5 \mathrm{~V}$ and a $V_{d c}=12 \mathrm{~V}$. The chamber pressure was

\section{fixed at 1.8 mTorr.}




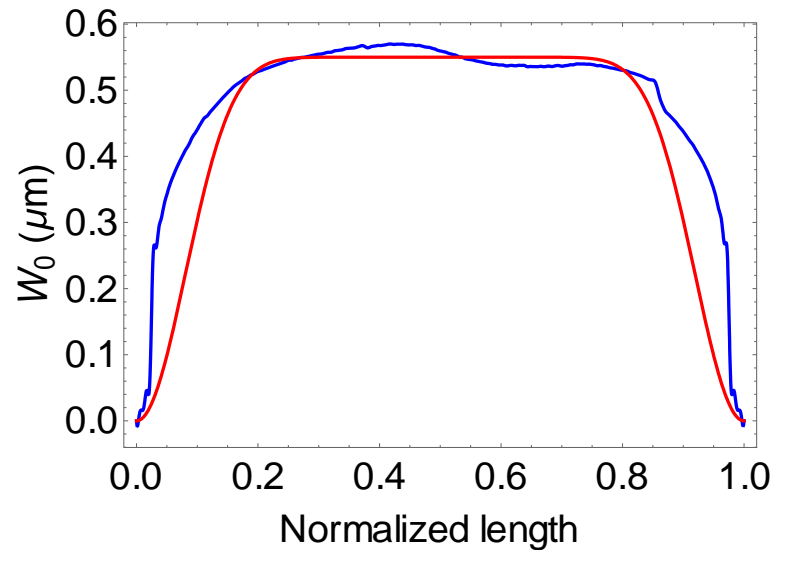

(a)

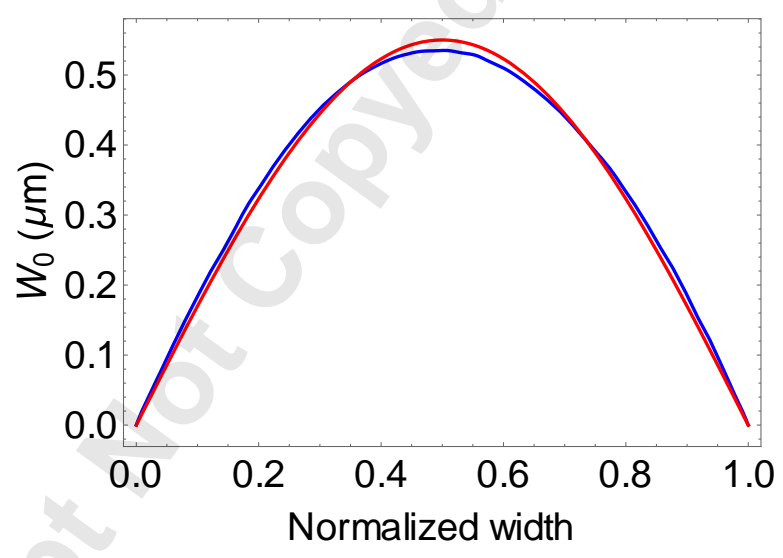

(b)

Figure 27: Initial curvature imperfection profiles at the center of the microplate; experimentally measured ' - ' and approximated '-', (a) along the length, (b) along the width. 


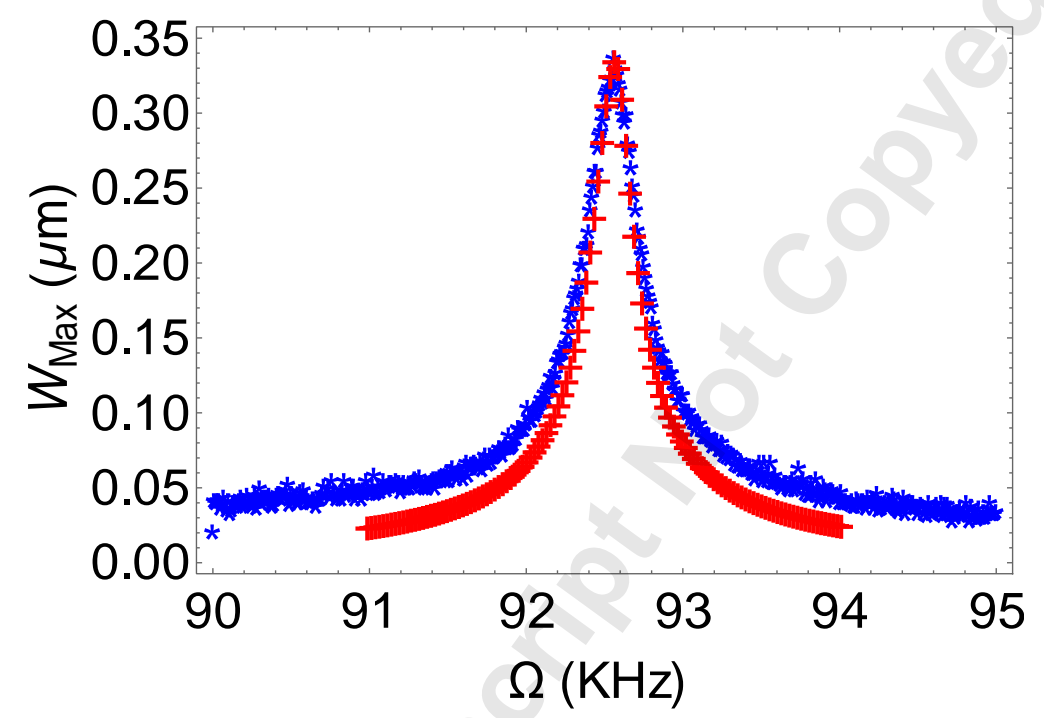

Figure 28: Frequency response plots of the microplate; theory ' + ' and the experiment '*', when actuated by a $V_{a c}=1 \mathrm{~V}$ and $V_{d c}=2 \mathrm{~V}$. A quality factor $Q=480$ was used for simulation. 


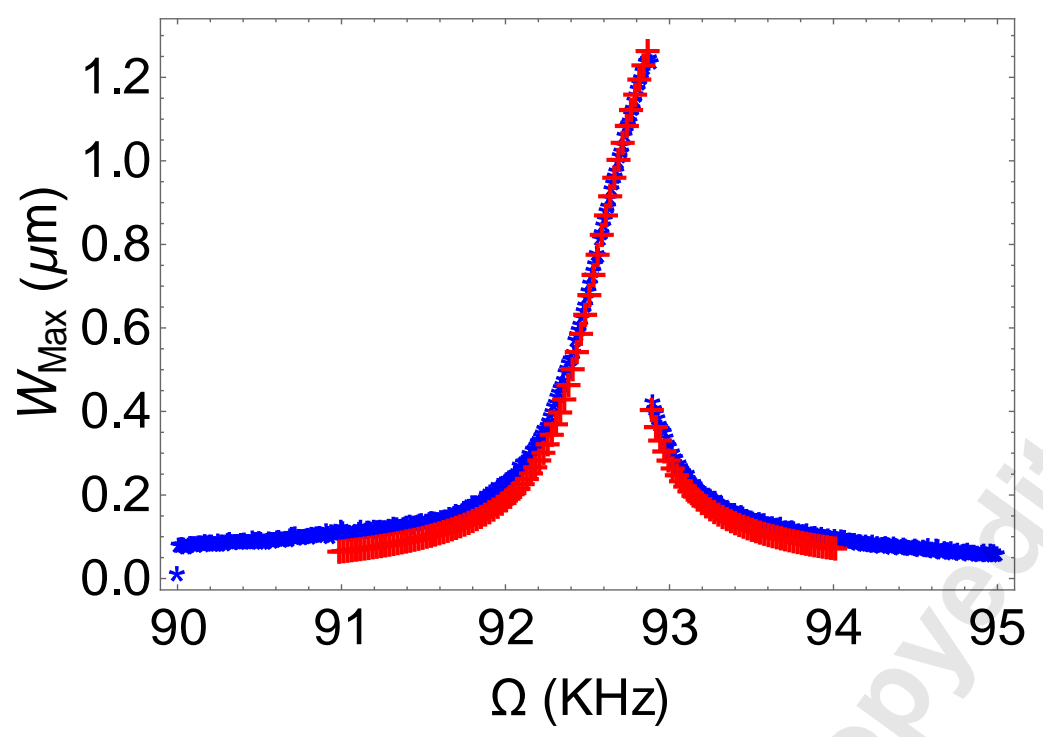

Figure 29: Frequency response plots of the microplate; theory ' + ’ and the experiment ' $*$ ', when actuated by a $\mathrm{V}_{\mathrm{ac}}=3 \mathrm{~V}$ and $\mathrm{V}_{\mathrm{dc}}=2 \mathrm{~V}$. A quality factor $Q=480$ was used for simulation. 


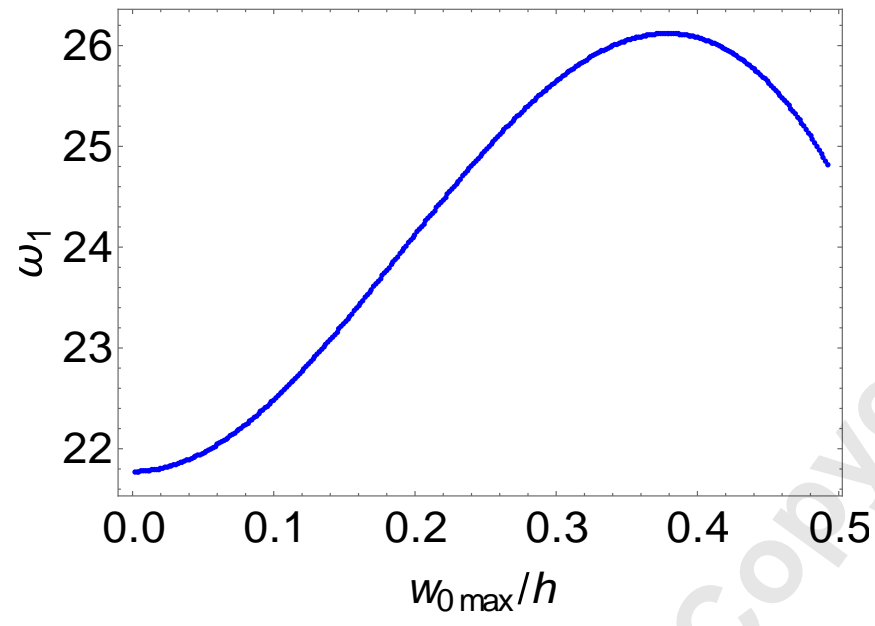

(a)

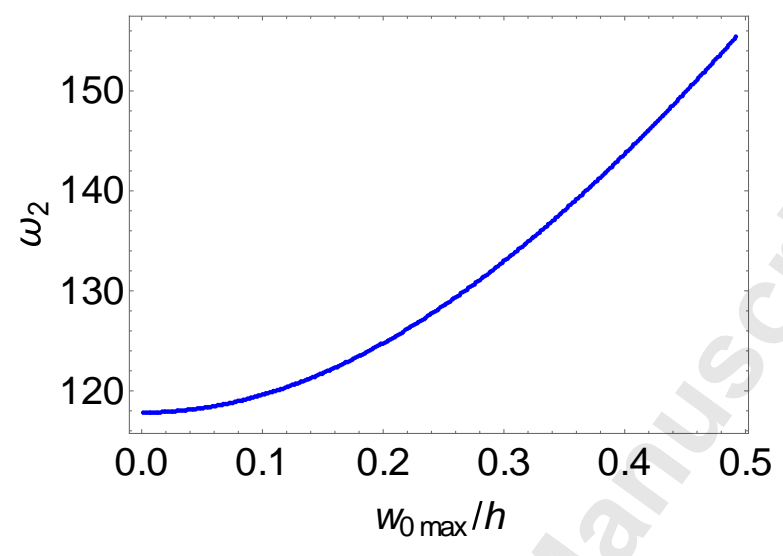

(b)

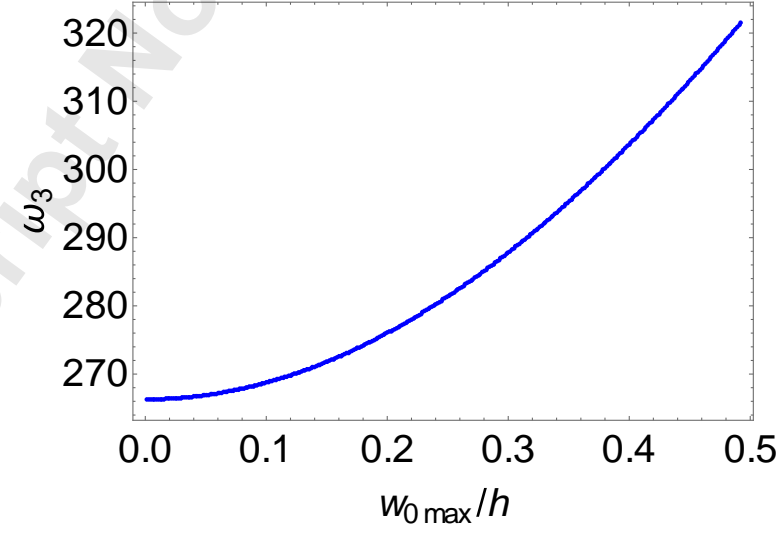

(c)

Figure 30: Variation of the natural frequency of the symmetric-symmetric modes of vibration with the maximum initial rise of the curvature imperfection. (a) First symmetric-symmetric mode. (b) Second symmetric-symmetric mode. (c) Third symmetric-symmetric mode. 
Table 5: Material and thickness information of the constituent layers of the microplate.

\begin{tabular}{|l|l|l|}
\hline Layer No. & Material & Thickness $(\mu \mathrm{m})$ \\
\hline 1 & Nickel & 0.45 \\
\hline 2 & Polyimide & 4.4 \\
\hline 3 & Chromium & 0.05 \\
\hline 4 & Gold & 0.25 \\
\hline 5 & Chromium & 0.05 \\
\hline
\end{tabular}


Table 6: Dimensional parameters of the microplate.

\begin{tabular}{|l|l|}
\hline Dimension & $(\mu \mathrm{m})$ \\
\hline Length $(a)$ & 500 \\
\hline Width $(b)$ & 150 \\
\hline Thickness $(h)$ & 5.2 \\
\hline Maximum initial deflection $\left(w_{0 \max }\right)$ & 0.55 \\
\hline Capacitor gap $(\mathrm{g})$ & 2 \\
\hline
\end{tabular}


Table 7: Perpendicular distance $\left(d_{i}\right)$ between the centroidal axis of the various layers and the microplate.

\begin{tabular}{|l|l|}
\hline \multicolumn{1}{|c|}{ Layers No. } & \multicolumn{1}{c|}{ Distance $d_{i}(\mu \mathrm{m})$} \\
\hline 1 & $\mathrm{~d}_{1}=2.375$ \\
\hline 2 & $\mathrm{~d}_{2}=0.05$ \\
\hline 3 & $\mathrm{~d}_{3}=2.275$ \\
\hline 4 & $\mathrm{~d}_{4}=2.425$ \\
\hline 5 & $\mathrm{~d}_{5}=2.575$ \\
\hline
\end{tabular}


Table 8: Material parameters of the various layers of the microplate.

\begin{tabular}{|l|l|l|l|}
\hline Material & Modulus of Elasticity, $E(\mathrm{GPa})$ & Poisson's Ratio, $v$ & Density, $\rho\left(\mathrm{kg} / \mathrm{m}^{3}\right)$ \\
\hline Nickel & 219 & 0.31 & 8900 \\
\hline Polyimide & 8.5 & 0.34 & 1400 \\
\hline Chromium & 279 & 0.21 & 7150 \\
\hline Gold & 70 & 0.44 & 19300 \\
\hline
\end{tabular}

